\title{
Data-Acquisition Systems: An Integral Part of Undergraduate Engineering and Technology Programs
}

\author{
David McDonald and Ajay Mahajan \\ Lake Superior State University
}

This paper describes example student projects and course activities in data-acquisition systems in undergraduate engineering and technology programs at Lake Superior State University. The focus of the paper is to show that students from electrical, computer and mechanical engineering as well as manufacturing engineering technology programs study and use modern dataacquisition systems in several courses as well as independent project work. Though LabVIEW software along with National Instruments data-acquisition boards are most commonly used, other systems such as SAGIAN Inc.'s CAMILLE system is used also in certain applications. It is shown that students in mechanical engineering and technology programs who have traditionally avoided electronics and computers have readily and enthusiastically taken to data-acquisition systems.

\section{Introduction}

The use of modern data acquisition systems that use virtual instruments (VIs) has increased dramatically in industry [1,2] in instrumentation and controls applications. This technology has influenced the design of modern test equipment with more intelligence "built directly into the machines of today for higher productivity and accuracy" [3]. In addition, manufacturing and process control industries are becoming PC converts in instrumentation and control" [4]. It is apparent that all areas of industry are changing to modern computer-based data-acquisition and control systems.

It is important that engineering and technology graduates obtain proficiency and confidence with modern computer-based data-acquisition systems. According to Steve Lekas, Vice President of New Products at IOTech, companies no longer have fully staffed departments to develop test systems and programs, hence technical employees need to "put their own test system together" [5]. All engineering and technology students, therefore, need to have a basic understanding of data-acquisition systems so they can correctly and confidently specify and use these systems after graduation.

The strategy to improve students' ability and confidence with modern computer-based instrumentation focused on integrating the use of this equipment into several courses. The target audience included all electrical, mechanical, and manufacturing majors in engineering and technology. The implementation plan involved introducing students to the use of this equipment in fundamentals courses, and then reinforcing its use in advanced courses, independent studies, 
research projects and a capstone senior projects course sequence.

Modern instrumentation equipment was therefore added to several laboratories so that the students would use it in both fundamental and advanced courses. The process of upgrading the instrumentation capability of these laboratories was supported by an Instrumentation and Laboratory Improvement (ILI) grant from the National Science Foundation (NSF), a curriculum development grant from the Society of Manufacturing Engineers (SME) Education Foundation and a grant for CAMILLIE data-acquisition system from Sagian Inc.

The courses at LSSU that incorporate data-acquisition systems are:

\begin{tabular}{|l|l|}
\hline Electrical and Computer Engineering: & $\begin{array}{l}\text { EE101 Introduction to Electrical Engineering } \\
\text { EE210 Circuits and Machines } \\
\text { EE425 Digital Signal Processing }\end{array}$ \\
\hline Mechanical Engineering: & $\begin{array}{l}\text { ME 320 Dynamics } \\
\text { ME430 Thermodynamics II and Heat Transfer } \\
\text { ME425 Vibrations }\end{array}$ \\
\hline Manufacturing Engineering Technology: & $\begin{array}{l}\text { RS460 Controls Engineering } \\
\text { RS480 Control Systems and Automation }\end{array}$ \\
\hline Independent Study Courses & EG490 Independent Study \\
\hline Senior Projects & EG491 Senior Design Projects 1 \\
& EG495 Senior Design Projects 2 \\
\hline Research Projects & \\
\hline
\end{tabular}

\section{Electrical and Computer Engineering}

The EE101 Introduction to Electrical Engineering course is designed to provide students with some fundamental computer skills and general information that will enhance their academic success. The course is organized as weekly units that are taught on a rotational basis by five electrical engineering faculty. The first unit helps the students get to know each other and the faculty, and other units develop students' computer skills. The remaining units help the students experience electrical engineering by providing experiential laboratory-based exercises in data acquisition, computer circuit simulation, machinery and power, microcontrollers, and robotics. Two units on data acquisition introduce LabVIEW programming and then use it to measure temperature.

EE210 Circuits and Machines is required for both electrical and mechanical majors. It introduces the basis of electrical circuits, machinery, and programmable logic controllers. An important aspect of this course is to become familiar with laboratory methods and equipment. The students are exposed to data acquisition as an important laboratory measurement and analysis tool. 
EE425 Digital Signal Processing uses data-acquisition systems extensively throughout the course in the form of laboratory exercises and student projects. Students typically collect and analyze data from motor tachometers and ultrasonic sensors to identify and isolate useful information in the signals. Further, they do independent projects in speech recognition, speaker identification, speed and position control of motors, etc. that require extensive data-acquisition. Typically, LabVIEW is used as the software in conjunction with National Instruments boards.

\section{Mechanical Engineering}

EM320 Dynamics is an important engineering fundamentals course. The students' learning of dynamics principles is improved when students complete quantitative dynamics laboratory exercises. The development of a dynamics laboratory included interesting and challenging laboratory exercises that used modern computer-based test equipment. As an example, students used proximity sensors and a data-acquisition to measure the time intervals of metallic objects as they traveled down ramps as well as projectile trajectories. All the experimental results are used to verify analytical results [6]. Also, a CCD camera is used to acquire visual pictures for some of the experiments.

The heat transfer course (ME430) is the third and final course to round of the students' knowledge in the fluid and thermal sciences. The heat transfer laboratory entails an innovative exercise that carries through most of the semester. The students analyze the cooling curve of a steel block in four different ways using analytical strategies. These are: 1) Lumped heat capacity systems, 2) Heisler charts, 3) Finite difference methods using MathCAD, and 4) Finite Element Analysis using ALGOR. Graphs are plotted for each strategy, and compared to results from an actual experiment in which the heated block is allowed to cool, and temperature data is collected using a temperature probe and a data-acquisition system [7]. Specifically LabVIEW is used for this experiment.

\section{Manufacturing Engineering Technology}

An automatic controls course RS460 is required for all electrical, mechanical, and manufacturing students. Laboratory exercises in this course were enhanced when students use data-acquisition systems to acquire, plot, and analyze data during various controls exercises. In addition, exercises in the use of data acquisition computer boards were included using data acquisition hardware and software that was acquired with the support of the SME equipment grant. Specifically LabVIEW and Matlab are used in the lab.

RS480 is a new course that is heavily dependent on modern computer software. Students learn to use four different softwares: Matlab and Simulink, LabVIEW, Program CC and Working Model. Further, students do independent projects for the course. Some of the projects done were:

1. Use of the CAMILLE system to monitor and control a process temperature.

2. Verification of the force and stress on a bow when shooting an arrow.

3. Verification of forces and momentum on balls on a pool table.

4. Simulation of an automobile clutch. 
5. Verification of the bending stress on a medical component.

6. Testing the performance of multiple alkaline batteries.

All the projects entailed the use of data-acquisition systems.

\section{Independent Study Courses}

Independent study opportunities are occasionally made available to selected senior students. On different occasions this type of course has been based on data acquisition. As an example, one senior student recently completed a computer instrumentation project that involved using LabVIEW to control and acquire data using IEEE-488. The project involved installing and configuring the GPIB board, and using LabVIEW to acquire data from a Fluke 45 meter and Fluke oscilloscope.

\section{Research Projects}

A group of students work on research projects in the Autonomous Systems Laboratory (ASL) which is a research facility in the School of Engineering and technology at LSSU. Currently the students are working on a 3D position estimation system that uses ultrasonics. This system uses one transmitter and multiple receivers to triangulate the position of the transmitter in space. All the data is collected using LabVIEW and then filtered and used in the algorithm that computes a 3D position for the transmitter.

\section{Senior Projects}

All the senior are required to go through a two-semester senior design experience. These two courses (EG491 and EG495) entail a lecture component and the completion of an industry-based project. These projects are solicited from industry and have a real dollar value associated with them. Some of the industries that participate in this program are Chrysler, GM, Dura Automotive, Delco, Takata, Mead Paper, etc. A fair number of these projects require dataacquisition components. For example projects from Takata and GM required the design and development of a portable data acquisition unit to test automotive modules and real time tests. Both the projects had budgets over $\$ 30,000$. Other projects may use data acquisition components in conjunction with other hardware and software.

\section{Conclusions}

This paper shows the implementation of data acquisition systems through out the engineering and engineering technology curriculum at LSSU. The authors believe that a well rounded education in data acquisition systems is essential for today's graduates. They further believe that no single course can accomplish this goal, hence the use of data acquisition systems has to be through out the curriculum for engineering and engineering technology students. This paper presents the courses and other opportunities that students have at LSSU to gain experience in data acquisition systems. 


\section{Acknowledgments}

Lake Superior State University acknowledges and appreciates an Instrumentation and Laboratory Improvement (ILI) grant from the National Science Foundation, "Improving the Laboratory Experience in Engineering Technology with Modern Computer-Based Instrumentation," DUE 9452284, a curriculum development grant from the Society of Manufacturing Engineers (SME) Education Foundation, and a grant from Sagian Inc.

\section{Bibliography}

1. Waterbury, R., "Software Trends Lead To Control Forefront," ISA INTECH, June, 1994, V41, N6.

2. Oliver, R. "Soft Instrumentation Transforms Interfaces," ISA INTECH, June 1994, V41, N6.

3. Michael Valenti, "Machine Tools get Smarter." Mechanical Engineering Magazine, Vol. 117, No. 11, November, 1995, pp. 70-75.

4. Schreier, P.G., Open fieldbus standards battle for dominance on the factory floor," Personal Engineering and Instrumentation News, December, 1996, p. 31.

5. Steve Lekas, "Searching for the Right Data Acquisition Software, Evaluation Engineering, Vol. 35, No. 12, December, 1996, pp. 14-20.

6. Mahajan, A., and McDonald, D., "Modern Instrumentation in the Dynamics Laboratory," DELOS NSF-ILI Poster Session, ASEE Annual Conference, Washington, DC, 1996.

7. Mahajan, A. and Valentine, A., "A Novel Multi-Faceted Approach to a Heat Transfer Laboratory using Modern Computer Tools," to be submitted to the Journal of Engineering Education, April 1998.

David McDonald is a Professor in the School of Engineering and Technology at Lake Superior State University. He is Chair of the Department of General Engineering and Engineering Technology, and teaches courses in Electrical Engineering and Engineering Technology. His primary interests are in control systems, data acquisition and control, and modern instrumentation.

Ajay Mahajan is an Associate Professor in the School of Engineering and Technology at Lake Superior State University. He is the Director of the Autonomous Systems Laboratory, which is a research facility in the School. His research interests are in robotics, controls, autonomous systems, artificial intelligence and machine learning. He is also actively involved in the development of innovative teaching methodologies for undergraduate and graduate education. 